УДК 633.88

\title{
НАКОПЛЕНИЕ ДИТЕРПЕНОВЫХ ГЛИКОЗИДОВ В ЛИСТЬЯХ РАЗНЫХ ГЕНОТИПОВ STEVIA REBAUDIANA BERTONI ПРИ ИЗМЕНЕНИИ ДЛИНЫ
}

\section{дня}

(C) А.А. Кочетов ${ }^{1}$, Н.В. Демина ${ }^{2}$ Н.В. Ульяновский ${ }^{3}$, З.А. Канарская ${ }^{2}$, А.В. Канарский"

${ }^{1}$ Агрофризический НИИ РАСХН, Гражданский пр., 14, Санкт-Петербург, 195220 (Россия), e-mail: kochetoval@yandex.ru

${ }^{2}$ Казанский национальный исследовательский технологический

университет, ул. К. Маркса, 68, Казань, Республика Татарстан, 420015

(Россия), e-mail: raxona@rambler.ru

${ }^{3}$ Северный (Арктический) федеральный университет им. М.В. Ломоносова, Набережная Северной Двины, 23, Архангельск, 163000 (Россия),

e-mail: uluanovskii_n@mail.ru

Stevia rebaudiana (Bertoni) - травянистый многолетний полукустарник семейства Asteraceae из Парагвая подробно изучается и интродуцируется в разные регионы мира. Листья стевии содержат дитерпеновые гликозиды - сладкие нетоксичные диетические вещества в 100-300 раз слаще сахарозы, которые используют в пищевой промышленности как замена сахару и синтетическим сахарозаменителям. Экстракты стевии оказывают фармакологическое действие. Известно о общетонизирующем, гипогликемическом и антигипертензивном действии, положительном влиянии стевии на пищеварение, подавлении грибкового и микробного роста, противоопухолевом эффекте.

В условиях регулируемой агроэкосистемы (светокультура) изучено влияние длины дня на накопление сухой надземной массы и содержание сладких гликозидов (стевиозид и ребаудиозид А) 10 генотипов стевии. Пробы проанализированы методом высокоэффективной жидкостной хроматографии с детектированием сигнала на гибридном массспектрометре. Показано, что сухая надземная масса растений, выращенных при 12 и 14 ч фотопериодах достоверно не различалась в то время, как при 16-часовом фотопериоде она значительно возрастала у всех генотипов. При увеличении длины дня с 12 до 16 ч света в сутки также наблюдали увеличение содержания суммы сладких гликозидов в листьях растений у всех генотипов. Причем наибольшую массу сладких гликозидов накапливали растения тех генотипов, которые имели более высокое процентное содержание сладких гликозидов в листьях, а не растения с большой надземной массой.

Выделены линии стевии, развивающие наибольшую сухую массу листьев, а также имеющие высокое процентное содержащие сладких гликозидов в листьях в условиях короткого и длинного дня. Полученные данные могут служить основой для проведения селекционной работы по созданию новых линий стевии с хозяйственно-ценными свойствами, адаптированных к конкретным световым условиям региона выращивания.

Ключевые слова: стевия (Stevia rebaudiana Bertoni), дитерпеновые гликозиды, стевиозид, ребаудиозида А, генотипы, фотопериод.

Работа выполнена с использованием оборудования ЦКП НО «Арктика» Северного (Арктического)

федерального университета имени М.В. Ломоносова.

\section{Введение}

Stevia rebaudiana (Bertoni) - травянистый многолетний полукустарник семейства Asteraceae в последние десятилетия подробно изучается и интродуцируется в разные регионы мира. Большой интерес к этому растению связан с использованием содержащихся в нем сладких диетических соединений - дитер-

Кочетов Алексей Александрович - заведующий лабораторией экологической генетики и селекции, кандидат биологических наук, e-mail: kochetoval@yandex.ru пеновых гликозидов, превосходящих по сладости сахарозу в 100-300 раз. Сладкие гликозиды стевии являются альтернативой синтетическим сахарозаменителям, безопасны для здоровья человека при

\footnotetext{
* Автор, с которым следует вести переписку.
} 
длительном употреблении, химически не разлагаются в человеческом организме [1]. В связи с увеличением числа больных диабетом во всем мире и небезопасности использования синтетических сахарозаменителей замена сахара на сладкие гликозиды стевии весьма актуальна.

Химический состав стевии достаточно хорошо изучен. На сегодняшний день известно около 34 энткауреновых гликозидов из листьев стевии, включая восемь изомеров стевиола и его производные [2]. Строение основных гликозидов стевии представлено на рисунке 1 и в таблице 1.

Содержание сладких гликозидов зависит от генотипа и условий выращивания и может варьировать от 4 до 20\% сухой массы листа, причем большая часть приходится на стевиозид и ребаудиозид А. Эти два основных гликозида содержатся преимущественно в листьях и обычно составляют 44-55 и 33-43\% от общего содержания сладких гликозидов соответственно [2, 3]. Энткауреновый скелет стевиозида и других сладких гликозидов стевии формируется так же, как и гиббериллины, по метилэритритолфосфатному (МЕР) пути биосинтеза изопреноидов $[4,5]$.

Разнообразие стевиолгликозидов является результатом действия на агликон стевиол различных гликозилтрансфераз [5]. В результате образуются соединения с разными органолептическими свойствами. Так, ребаудиозид А значительно слаще стевиозида и не имеет неприятного привкуса. Замена глюкозы в положении С2’ на рамнозу приводит к образованию дулькозида А, а в положении С3' - к образованию ребаудиозида С, снижает интенсивность сладости образовавшихся гликозидов [6].

Особый интерес для интродукции и селекции представляют различия по содержанию и составу сладких гликозидов у разных генотипов стевии. Показано, что сумма сладких гликозидов у растений разных генотипов стевии при уборке может сильно варьировать, составляя от 6,7 до $18,6 \%$ (среднее $12,2 \%$ ) сухой массы листьев. Различия между растениями по содержанию сладких гликозидов в гибридных популяциях еще больше [2].

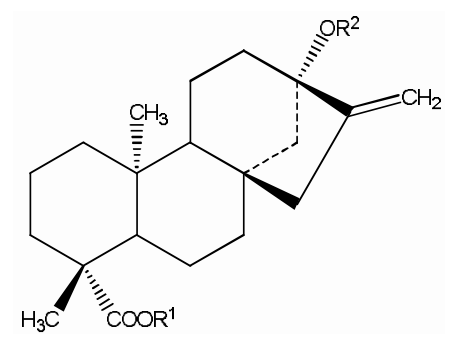

Рис. 1. Общая формула молекул сладких гликозидов [3]

Таблица 1. Функциональные группы в молекулах сладких гликозидов стевии [3]

\begin{tabular}{|c|c|c|}
\hline Название гликозида & $\mathrm{R}_{1}$ & $\mathrm{R}_{2}$ \\
\hline Стевиол & $\mathrm{H}$ & $\mathrm{H}$ \\
\hline Стевиолбиозид & $\mathrm{H}$ & $\beta-$ Glc- $\beta-G l c(2 \rightarrow 1)$ \\
\hline Стевиозид & $\beta-G l c$ & $\beta-G l c-\beta-G l c(2 \rightarrow 1)$ \\
\hline Ребаудиозид А & $\beta-G l c$ & $\beta$-Glc- $\beta$-Glc $(2 \rightarrow 1)$ \\
\hline Ребаудиозид В & $\mathrm{H}$ & $\begin{array}{l}\beta-\operatorname{Glc}(3 \rightarrow 1) \\
\beta-\operatorname{Glc}-\beta-\operatorname{Glc}(2 \rightarrow 1) \\
\beta-\operatorname{Glc}(3 \rightarrow 1)\end{array}$ \\
\hline $\begin{array}{l}\text { Ребаудиозид C } \\
\text { (дулькозид В) }\end{array}$ & $\beta-G l c$ & $\begin{array}{l}\beta-\operatorname{Glc}-\alpha-\operatorname{Rha}(2 \rightarrow 1) \\
\beta-\operatorname{Glc}(3 \rightarrow 1)\end{array}$ \\
\hline Ребаудиозид D & $\beta-G l c-\beta-G l c(2 \rightarrow 1)$ & $\begin{array}{l}\beta-\operatorname{Glc}-\beta-\operatorname{Glc}(2 \rightarrow 1) \\
\beta-\operatorname{Glc}(3 \rightarrow 1)\end{array}$ \\
\hline Ребаудиозид Е & $\beta$-Glc- $\beta$-Glc $(2 \rightarrow 1)$ & $\beta-$ Glc- $\beta-$ Glc $(2 \rightarrow 1)$ \\
\hline Ребаудиозид F & $\beta-G l c$ & $\begin{array}{l}\beta-\mathrm{Glc}-\beta-\mathrm{Xyl}(2 \rightarrow 1) \\
\beta-\mathrm{Glc}(3 \rightarrow 1)\end{array}$ \\
\hline Дулькозид А & $\beta-G l c$ & $\beta$-Glc- $\alpha-\operatorname{Rha}(2 \rightarrow 1)$ \\
\hline
\end{tabular}

Примечание. Glc - D-глюкоза, Rha - рамноза, Xyl - ксилоза

Наблюдаемые различия зависят как от генотипа растений, так и от условий их выращивания. Для более четкого выявления влияния генотипа на накопление сладких гликозидов стевии нами проведены опыты в регулируемых условиях, где варьирование экологических факторов сведено к минимуму. Изучено содержание сладких гликозидов в листьях разных генотипов стевии при изменении продолжительности суточного освещения. Такие данные необходимы для создания новых линий стевии, перспективных для промышленного выращивания, адаптированных к конкретным световым условиям региона возделывания.

Демина Надежда Валерьевна - аспирант кафедры пищевой инженерии, e-mail: raxona@rambler.ru Ульяновский Николай Валерьевич - младший научный сотрудник центра коллективного пользования научным оборудованием «Арктика», e-mail: uluanovskii_n@mail.ru Канарская Зося Альбертовна - доцент кафедры пищевой биотехнологии, e-mail: zosya_kanarskaya@mail.ru Канарский Альберт Владимирович - профессор кафедры пищевой биотехнологии, e-mail: alb46@mail.ru

\section{Экспериментальная часть}

В опытах использовали растения разных генотипов стевии из коллекции Агрофизического института (Санкт-Петербург), отличающиеся морфологически и по реакции на физические стрессоры. Образцы генотипов отобраны в популяции 
растений, выращенных из семян различного происхождения. Главными критериями отбора были устойчивость к комплексу стрессоров в регионе интродукции (Ленинградская область) и высокие показатели компонентов продуктивности (размер и масса листьев, кущение). Описания генотипов приведены в таблице 2.

Как показали наши предыдущие исследования, антиоксидантная активность и содержание полифенолов в листьях у отобранных генотипов были высокими, но существенных различий между ними по этим показателям не наблюдали [7, 8]. Для опытов использовали зеленые черенки с 3-4 парами листьев, которые срезали с маточных растений каждого генотипа, укореняли и высаживали в 0,5 л горшки с торфо-песчаной смесью (1 : 1 по объему). После одной недели адаптации укорененные черенки переставляли в светоизолированные кабинки на разные фотопериоды - 12, 14 и 16 ч света в сутки. Облученность растений в опыте составляла-50-70 Вт/м² ФАР под лампами ДНаТ-400. Температура в кабинках - 25-28 ${ }^{\circ} \mathrm{C}$. Растения поливали один раз в день 1 н раствором Кнопа, чередуя его с водой. После 45 дней выращивания растения убирали, измеряли надземную массу (сырую и сухую), массу сухих листьев и стеблей, число стеблей на растении, число пар листьев на стебле и размеры сформированного листа в средней части стебля. Образцы для химического анализа брали с 5-6 растений каждого генотипа, используя все листья, которые измельчали до порошкообразного состояния. Экстракцию сладких гликозидов из этих образцов проводили с использованием установки для ускоренной экстракции ASE 350 (Dionex, CША). C этой целью навеску измельченного сухого образца массой 0,1 г помещали в ячейку объемом 1 мл. Экстрагирование проводили водой при температуре $60^{\circ} \mathrm{C}$ и давлении 1700 psi в 2 цикла по 10 мин каждый [9]. Далее измеренный объем полученного экстракта фильтровали через нейлоновый фильтр с порами диаметром 0,22 мкм, разбавляли метанолом в 2 раза и вводили в хроматографическую систему. Пробы проанализированы методом высокоэффективной жидкостной хроматографии с детектированием сигнала на гибридном масс-спектрометре QTRAP 3200 (ABSciex, США). Хроматографическое разделение производилось на ВЭЖХ системе Ultimate 3000 (Dionex, CША) в изократическом режиме. В качестве подвижной фазы использовали 10 мМ водный раствор формиатного буфера (Раствор А) и ацетонитрил (Раствор В) в соотношении $15: 85$ соответственно.

Таблица 2. Характеристика растений разных генотипов стевии, выращенных в открытом грунте (2009-2010 гг.)

\begin{tabular}{|c|c|c|c|c|}
\hline $\begin{array}{l}\text { № генотипа } \\
\text { в опыте }\end{array}$ & $\begin{array}{c}\text { Селекци- } \\
\text { онный номер }\end{array}$ & $\begin{array}{c}\text { Происхождение об- } \\
\text { разца (выращен } \\
\text { из семян фирмы) }\end{array}$ & Морфологические особенности образца & $\begin{array}{c}\text { Средние размеры } \\
\text { листа, мм }\end{array}$ \\
\hline 1 & 2.7 & «Richters», Канада & $\begin{array}{l}\text { Куст невысокий, с 2-5 побегами. Лист } \\
\text { крупный удлиненный ланцетовидный, край } \\
\text { листа пильчатый, междоузлия близко распо- } \\
\text { ложенные }\end{array}$ & $\begin{array}{l}111 \times 55^{*} \\
106 \times 47^{* *}\end{array}$ \\
\hline 2 & 5.5 & «Richters», Канада & $\begin{array}{l}\text { Куст высокий, с 2-7 побегами. Лист круп- } \\
\text { ный, ромбовидный, край листа пильчатый }\end{array}$ & $\begin{array}{c}123 \times 64 * \\
117 \times 51 * *\end{array}$ \\
\hline 3 & ГБ & «Грин Бэлт», Россия & $\begin{array}{l}\text { Куст средней высоты, с 2-4 побегами, хо- } \\
\text { рошо облиствленный. Лист мелкий, ланцет- } \\
\text { ный, зубцы края листа слабовыраженные }\end{array}$ & $64 \times 31 * *$ \\
\hline 4 & A9 & «Richters», Канада & $\begin{array}{l}\text { Растение невысокое, хорошо кустящееся (3- } \\
4 \text { побега). Лист мелкий, ланцетный и ромби- } \\
\text { ческий, зубцы края листа острые }\end{array}$ & $\begin{array}{l}100 \times 44 * \\
92 \times 37 * *\end{array}$ \\
\hline 5 & 3.7 & «Richters», Канада & $\begin{array}{l}\text { Куст высокий, среднекустистый. Лист круп- } \\
\text { ный, ромбовидный, зубцы края листа острые }\end{array}$ & $103 \times 57 *$ \\
\hline 6 & $2 \times 3$ & «Richters», Канада & $\begin{array}{l}\text { Растение высокое с 2-6 побегами. Лист сред- } \\
\text { ний ромбовидный, край листа пильчатый }\end{array}$ & $\begin{array}{l}108 \times 51 * \\
99 \times 41 * *\end{array}$ \\
\hline 7 & A10 & «Richters», Канада & $\begin{array}{l}\text { Куст средней высоты с 1-3 побегами. Лист } \\
\text { средней величины, ромбовидный с пильча- } \\
\text { тым краем }\end{array}$ & $\begin{array}{l}89 \times 56 * \\
95 \times 51 * *\end{array}$ \\
\hline 8 & $\mathrm{X} 2$ & «Richters», Канада & $\begin{array}{l}\text { Растение невысокое, хорошо кустится (3-6 } \\
\text { побегов). Лист крупный, ромбовидный, зуб- } \\
\text { цы листа острые }\end{array}$ & $\begin{array}{c}- \\
122 \times 56 * *\end{array}$ \\
\hline 9 & A15 & «Richters», Канада & $\begin{array}{l}\text { Куст средней высоты с 1-3 побегами. Лист } \\
\text { средний, ромбовидный, зубцы листа округлые }\end{array}$ & $95 \times 46^{*}$ \\
\hline 10 & 4.3 & «Richters», Канада & $\begin{array}{l}\text { Куст средней высоты с 1-3 побегами. Лист } \\
\text { крупный, ромбовидный, зубцы листа заост- } \\
\text { ренные }\end{array}$ & $\begin{array}{l}107 \times 48 * \\
88 \times 43 * *\end{array}$ \\
\hline
\end{tabular}


Для разделения использовали колонку Nucleodur HILIC (Mancherey-Nagel, Германия) 150×3 мм, размер частиц -3,5 мкм, размер пор - 120 А. Колонку термостатировали при температуре $40{ }^{\circ} \mathrm{C}$, скорость потока подвижной фазы составила 0,7 мл/мин, объем вводимой пробы - 2 мкл [10]. Для анализа стевиозида и ребаудиозида на масс-спектрометре оптимизированы параметры ионизации веществ при помощи прямого ввода в масс-детектор. По результатам оптимизации выбраны следующие MRM-переходы: 803 $\rightarrow 641$ для стевиозида, 965 $\rightarrow 803$ для ребаудиозида А [11]. Калибровочная зависимость построена по площади пика MRM-переходов от концентрации исследуемых веществ в растворе. Концентрация калибровочных растворов варьировалась в диапазоне от 1 до 250 мг/л. Обработка результатов проведена с использованием ПО MultiQuant. Относительная погрешность анализа составила - 15\%.

\section{Обсуждение результатов}

Масса сладких гликозидов в растениях стевии зависит от накопления ими сухой массы листьев и процентного содержания сладких гликозидов в листьях (содержание гликозидов в стебле незначительно). Анализ результатов экспериментов показывает, что накопление сухой надземной массы и массы листьев при изменении фотопериода носит сходный характер у разных генотипов. Сухая масса растений, выращенных при 12 и 14 часовом фотопериодах, достоверно не различалась, в то время как при 16-часовом фотопериоде она значительно возрастала у всех генотипов (рис. 2). Для показателя содержания сладких гликозидов наблюдалась та же тенденция - увеличение процентного содержания при увеличении длины дня. Такое положительное влияние длинного дня на хозяйственнно-ценные свойства стевии, подтвержденное реакцией разных генотипов, подкрепляет наш тезис о перспективности выращивания этой культуры в Нечерноземье [12], где в летнее время продолжительность суточного освещения превышает 14 ч, а продуктивность растений лимитируется преимущественно продолжительностью теплого летнего периода.

Несмотря на общую тенденцию к увеличению продуктивности растений стевии при увеличении длины дня между растениями разных генотипов выявлены существенные различия по накоплению надземной массы, содержанию стевиозида и ребаудиозида А на разных фотопериодах (табл. 3). Так, при 12часовом фотопериоде наибольшую массу сухих листьев накапливали растения генотипов №5, 1 и 6 (2,5; 2,8 и 3,0 г соответственно). При 14-часовом фотопериоде к генотипам №1 и 6 добавлялись генотипы №3 и 8 (2,8-3,0 г/раст.). Лучшую продуктивность при 16-часовой длине дня наблюдали у растений генотипов №1, 3 и 4 (5,4; 4,4 и 4,5 г сухого листа на растение соответственно).

Важным хозяйственно-ценным показателем для стевии является процентное содержание сладких гликозидов в листе, а также соотношение ребаудиозида А и стевиозида. Различия между генотипами по этим компонентам (средние показатели по 3 фотопериодам) представлены на рисунке 3. Самым высоким процентным содержанием сладких гликозидов в листе характеризовались генотипы №7 и 9. За счет этого растения данных вариантов накапливали и наибольшую среди остальных генотипов массу сладких гликозидов. Генотипы же с высокими показателями накопления сухой надземной массы и массы сухих листьев, но средним процентным содержанием сладких гликозидов в листе, имели значительно меньшую массу сладких гликозидов. Различия между генотипами по реакции на длину дня наиболее сильно проявились по суммарному показателю - масса сладких гликозидов в растении. Так, при 16-часовом фотопериоде лучшими оказались растения варианта №7 (383 мг сладких гликозидов), при 14-часовом фотопериоде - растения варианта №3 (173 мг), а при 12-часовм фотопериоде - №1 (86 мг). Для образца №4 отмечено аномально низкое содержание ребаудиозида А $(0,2 \%)$ на всех фотопериодах, а для образца №9 - несколько более высокое по сравнению с другими $(1,8-2,6 \%)$. Наилучшее соотношение ребаудиозида А и стевиозида было обнаружено у образца №3 $(0,63)$.

Проведенные исследования выявили существенные различия между генотипами стевии как по накоплению ими сухой надземной массы, так и по содержанию сладких гликозидов в листьях при разных фотопериодах. Полученные данные могут служить основой для проведения селекционной работы по созданию новых линий стевии с хозяйственно-ценными свойствами, адаптированных к конкретным световым условиям региона выращивания.

Таблица 3. Варьирование показателей продуктивности и содержания сладких гликозидов у растений разных генотипов стевии, выращенных при разной длине дня

\begin{tabular}{c|c|c|c|c}
\hline Фотопериод & $\begin{array}{c}\text { Сухая надземная } \\
\text { масса, г/раст. }\end{array}$ & $\begin{array}{c}\text { Масса сухих } \\
\text { листьев, г/раст. }\end{array}$ & $\begin{array}{c}\text { Содержание стевиозида } \\
\text { в сухих листьях, \% }\end{array}$ & $\begin{array}{c}\text { Содержание ребаудиозида } \\
\text { А в сухих листьях, \% }\end{array}$ \\
\hline 12 ч & $2,63 \div 5,64$ & $1,2 \div 2,9$ & $1,61 \div 5,77$ & $0,2 \div 2,56$ \\
14 ч & $2,72 \div-6,37$ & $1,19 \div 3,03$ & $2,23 \div 6,42$ & $0,2 \div 1,87$ \\
16 ч & $4,54 \div 9,04$ & $2,76 \div 5,38$ & $3,11 \div 6,06$ & $0,59 \div 3,29$ \\
\hline
\end{tabular}




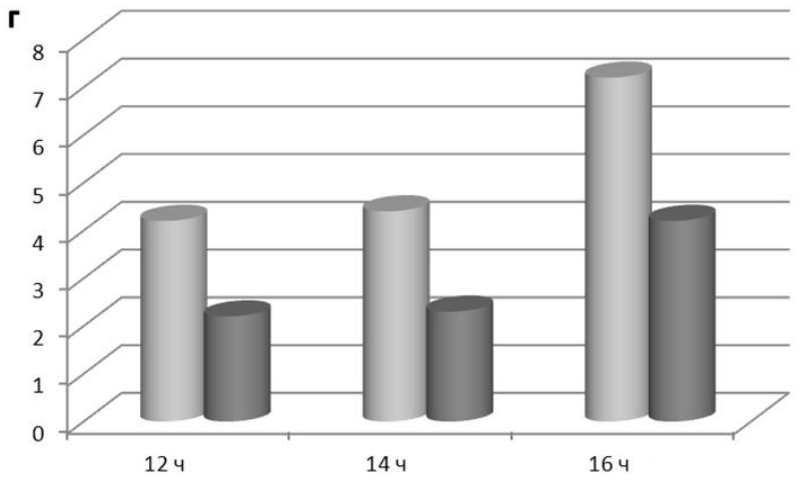

Рис. 2. Средняя сухая масса растений стевии при разной длине дня. $\square$ - общая надземная масса;

- масса листьев

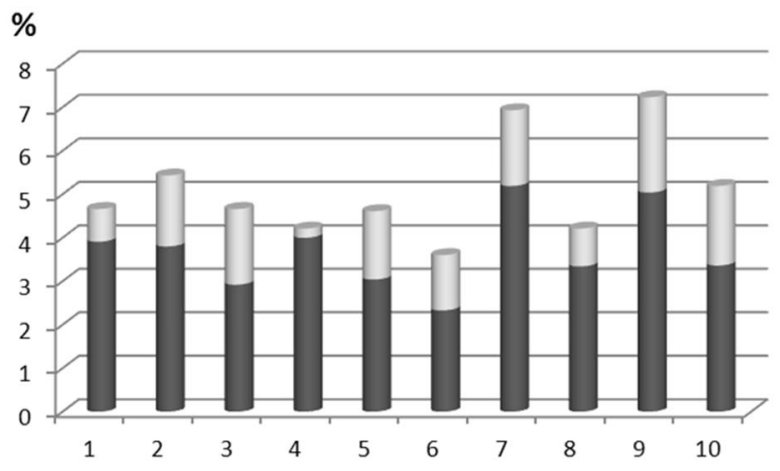

Рис. 3. Среднее содержание стевиозида и ребаудиозида А в сухом листе у разных генотипов стевии (1-10 - номера генотипов стевии в опыте).

- ребаудиозид А; - стевиозид

\section{Выводbl}

1. Изменение длины дня с 12 до 16 ч света в сутки приводило к увеличению накопления сухой надземной массы, массы сухих листьев и процентного содержания сладких гликозидов в листьях у растений разных генотипов стевии.

2. Выявлены существенные различия между генотипами стевии по реакции на длину дня, главным образом, по накоплению сухой надземной массы и содержанию сладких гликозидов. Наибольшую надземную массу при всех фотопериодах развивали растения генотипа №1. Однако наибольшую массу сладких гликозидов накапливали растения генотипов №7 и 9 за счет более высокого процентного содержания сладких гликозидов в их листьях.

\section{Список литературы}

1. Kinghorn A.D., Wu C. D., Soejarto D. D. In Alternative Sweeteners, 3 ed., revised and expanded. L. O’Brien Nabors (Ed.), Marcel Dekker, New York, 2001. Pp. 167-184.

2. Ceunen S., Geuns J. Influence of photoperiodism on the spatio-temporal accumulation of steviol glycosides in Stevia rebaudiana(Bertoni) // Plant Science. 2013. Vol. 198. Pp. 72-82.

3. Geuns J.M.C. Molecules of Interest. Stevioside // Phytochemistry. 2003. N64. Pp. 913-921.

4. Totte N., Charon L., Rohmer M., Compernolle F., Baboeuf I., Geuns J.M.C. Biosynthesis of the diterpenoid steviol, an entkaurene derivative from Stevia rebaudiana Bertoni, via the methylerythritol phosphate pathway // Tetrahedron Letters. 2000. N41. Pp. 6407-6410.

5. Brandle J.E., Telmer P.G. Steviol glycoside biosynthesis // Phytochemistry. 2007. Vol. 68, N14. Pp. 1855-1863.

6. Tanaka O. Improvement of taste of natural sweeteners // Pure Appl. Chem. 1997. N69. Pp. 675-683.

7. Демина Н.В., Кочетов А.А., Шевченко Я.А., Канарский А.В., Канарская З.А. Изучение антиоксидантной активности экстрактов из листьев различных генотипов стевии, выращенных в светокультуре // Вестник Казанского технологического университета. 2013. Т. 16, №20. С. 144-147.

8. Демина Н.В., Кочетов А.А., Шевченко Я.А., Сметанская И.Н., Канарский А.В., Канарская З.А. Полифенольные вещества экстрактов стевии // Вестник Казанского технологического университета. 2013. Т. 16, №23. С. 124-126.

9. Xia-ye X., Shang-wei C., Jin-shui C., Sheng-fang W., Li-ping W., Rui-peng Y. Extraction of three main steviosides using ASE from Stevia rebaudiana Bertoni // Food \& Machinery. 2012. N5. Pp. 125-128.

10. Zimmermann B.F., Woelwer-Rieck U., Papagiannopoulos M. Separation of Steviol Glycosides by Hydrophilic Liquid Interaction Chromatography // Food Analytical Methods. 2012. Vol. 5, N2. Pp. 266-271.

11. Shafii B., Vismeh R., Beaudry R., Warner R, Daniel Jones A. Large-scale profiling of diterpenoid glycosides from Stevia rebaudiana using ultrahigh performance liquid chromatography/tandem mass spectrometry // Analytical \& Bioanalytical Chemistry. 2012. Vol. 403, N9. Pp. 2683-2690.

12. Кочетов А.А. Перспективы выращивания стевии [Stevia rebaudiana Bertoni (L.)] в Нечерноземной зоне России // Аграрная Россия. 2012. №2. С. 2-4. 
Kochetov A.A. ${ }^{l}$, Demina N.V. ${ }^{2}$, Ul'ianovskii N.V. ${ }^{3}$, Kanarskaia Z.A. ${ }^{2}$, Kanarskii A.V. ${ }^{2 *}$ ACCUMULATION DITERPENE GLYCOSIDES IN LEAVES OF DIFFERENT GENOTYPES STEVIA REBAUDIANA BERTONI CHANGE IN LENGTH OF THE DAY

${ }^{1}$ Agrophysical Research Institute, Grazhdanskiy pr., 14, St. Petersburg, 195220 (Russia),

e-mail: kochetoval@yandex.ru

${ }^{2}$ Kazan State Technological University, K. Marksa st., 8/31, Kazan, Republic of Tatarstan, 420015 (Russia), e-mail: raxona@rambler.ru

${ }^{3}$ Northern (Arctic) Federal University M.V. Lomonosov, Naberezhnaia Severnoi Dviny, 23, Arkhangelsk,163000,

(Russia),e-mail: uluanovskii_n@mail.ru

Stevia rebaudiana (Bertoni) is the Paraguayan perennial shrub, belongs to Asteraceae family is well investigated and introduced in different regions of the world. The leaves of the stevia plants contain diterpene glycosides - sweet non-toxic dietic substances that are in 100-300 times sweeter than sucrose, which are used in food industry as the substitute of sugar and synthetic sweeteners. Extracts of a stevia have pharmacological effect. The all-toning, hypoglycemic and antigipertensive action, positive influence of a stevia on digestion, suppression of fungal and microbic growth, antineoplastic effect are well known.

The effect of duration of photoperiod on the accumulation of dry mass and the content sweet glycosides was studied on 10 genotypes of stevia in the controlled conditions. Samples are analysed by method of a highly effective liquid chromatography with detecting of a signal on a hybrid mass spectrometer. It was revealed that the dry mass of the plants, which were cultivated under 12 and 14- hours photoperiods, authentically didn't differ while under the 16-hour photoperiod it considerably increased in all the studied genotypes. The change of photoperiod from 12 to 16 hours light per day also resulted in increasing of the amount of sweet glycosides in leaves of plants of genotypes studied. A significant variability is seen in the percentage composition of steviol glycosides. The greatest mass of sweet glycosides was accumulated by plants of those genotypes which had higher percentage of sweet glycosides in leaves, but not the greatest dry mass of leaves. The lines of a stevia which are accumulated the greatest dry mass of leaves, and also having high percentage containing sweet glycosides in leaves under the of short and long- day conditions are allocated. The obtained data can form a basis for carrying out the selection of new lines of stevia with valuable properties, adapted to the lighting conditions of the region of cultivation.

Keywords: Stevia rebaudiana Bertoni, diterpene glycosides, stevioside, rebaudioside A, genotype, photoperiod.

\section{References}

1. Kinghorn A.D., Wu C.D., Soejarto D.D. In Alternative Sweeteners, 3 ed., revised and expanded. L. O'Brien Nabors (Ed.), Marcel Dekker, New York, 2001, pp. 167-184.

2. Ceunen S., Geuns J. Plant Science, 2013, vol. 198, pp. 72-82.

3. Geuns J.M.C. Phytochemistry, 2003, no. 64, pp. 913-921.

4. Totte N., Charon L., Rohmer M., Compernolle F., Baboeuf I., Geuns J.M.C. Tetrahedron Letters, 2000, no. 41, pp. 6407-6410.

5. Brandle J.E., Telmer P.G. Phytochemistry, 2007, vol. 68, no. 14, pp. 1855-1863.

6. Tanaka O. Pure Appl. Chem., 1997, no. 69, pp. 675-683.

7. Demina N.V., Kochetov A.A., Shevchenko Ia.A., Kanarskii A.V., Kanarskaia Z.A. Vestnik Kazanskogo tekhnologicheskogo universiteta, 2013, vol. 16, no. 20, pp. 144-147. (in Russ.).

8. Demina N.V., Kochetov A.A., Shevchenko Ia.A., Smetanskaia I.N., Kanarskii A.V., Kanarskaia Z.A. Vestnik Kazanskogo tekhnologicheskogo universiteta, 2013, vol. 16, no. 23, pp. 124-126. (in Russ.).

9. Xia-ye X., Shang-wei C., Jin-shui C., Sheng-fang W., Li-ping W., Rui-peng Y. Food \& Machinery, 2012, no. 5, pp. $125-128$.

10. Zimmermann B.F., Woelwer-Rieck U. Food Analytical Methods, 2012, vol. 5, no. 2, pp. 266-271.

11. Shafii B., Vismeh R., Beaudry R., Warner R, Daniel Jones A. Analytical \& Bioanalytical Chemistry, 2012, vol. 403, no. 9, pp. 2683-2690.

12. Kochetov A.A. Agrarnaia Rossiia, 2012, no. 2, pp. 2-4. (in Russ.).

Received September 23, 2014

Revised March 7, 2015

\footnotetext{
* Corresponding author.
} 